\title{
ANALISIS DESAIN FORMULIR RESUME MEDIS DITINJAU DARI ASPEK FISIK ISI DAN ANATOMI DI UNIT RAWAT INAP UPTD PUSKESMAS KARTASURA
}

\author{
Yustika Ayu Okta ${ }^{1 *}$, Arifatun Nisaa ${ }^{2}$ Julia Pertiwi $^{3}$ \\ ${ }^{123}$ Prodi Rekam Medis dan Informasi Kesehatan, Fakultas Kesehatan Masyarakat \\ Universitas Veteran Bangun Nusantara \\ *email : yustikaayu124@ gmail.com
}

\begin{abstract}
Incomplete filling out inpatient forms can lead to loss of informative function of medical record documents. One of the causes of incomplete form filling is ineffective and efficient form design. The purpose of this study was to analyze the design of the medical resume form at the UPTD Puskesmas Kartasura in terms of anatomy, physical and content aspects. This study used a qualitative research design with a case study approach. This research was conducted in March-April 2020 at the UPTD Puskesmas Kartasura. The research subjects were emergency room doctors, nurses and medical record officers. The object of this research is inpatient medical resume form. Data collection was carried out by observation and interviews. The validation technique of data validity in this qualitative study used triangulation of sources. The results of the study concluded that the medical resume form design was not yet effective and efficient because $100 \%$ of the forms were not completely filled. The conclusion in this research is that a new form design is needed by completing the missing form items such as the form edition number and page number, introduction, notes and instructions.
\end{abstract}

Keywords: Analysis, Design forms, Medical resume forms, Health center

\begin{abstract}
ABSTRAK
Ketidaklengkapan pengisian formulir rawat inap dapat menyebabkan hilangnya fungsi informatif dokumen rekam medis.Salah satu penyebab pengisian formulir yang tidak lengkap adalah desain formulir yang tidak efektif dan efisien. Tujuan penelitian ini adalah menganalisis desain formulir resume medis di UPTD Puskesmas Kartasura ditinjau dari aspek anatomi, fisik dan isi. Penelitian ini menggunakan desain penelitian kualitatif dengan pendekatan studi kasus.Penelitian ini dilaksanakan pada bulan Maret-April 2020 di UPTD Puskesmas Kartasura.Subjek penelitian adalah dokter IGD, perawat dan petugas rekam medis. Objek yang diambil dalam penelitian ini adalah formulir resumemedis pasien rawat inap. Pengumpulan data dilakukan dengan observasi dan wawancara.Teknik validasi keabsahan data pada penelitian kualitatif ini menggunakan triangulasi sumber. Hasil penelitian dapat disimpulkan bahwa desain formulir resume medis belum efektif dan efisien karena 100\% formulir tidak terisi dengan lengkap. Kesimpulan dalam penelitian ini adalah diperlukan desain baru formulir dengan melengkapi item formulir yang belum ada seperti nomor edisi formulir dan nomor halaman, introduction, catatan dan instruction.
\end{abstract}

Kata kunci: Analisis, Desain formulir, formulir resume medis, Puskesmas 


\section{PENDAHULUAN}

Setiap fasilitas kesehatan baik dari tingkat primer atau pratama, sekunder, tersier wajib menyelenggarakan rekam medis dengan tujuan tercapainya tertib administrasi, pendokumentasian pelayanan yang telah diberikan oleh tenaga kesehatan kepada pasien.Salah satunya adalah Pusat Kesehatan Masyarakat (Puskesmas) sebagai bentuk layanan tingkat pratama bagi pasien.Pelayanan kesehatan yang diberikan dapat berupa pelayanan medis dan non-medis seperti pelayanan rekam medis.

Puskesmas Kartasura, Sukoharjo merupakan salah satu Puskesmas yang telah mendapatkan Akreditasi Paripurna. Pemberian pelayanan yang bermutu sudah menjadi kewajiban Puskesmas baik pelayanan medis dan non medis seperti pelayanan terhadap dokumen rekam medis pasien.Berdasarkan studi pendahuluan yang dilakukan pada Bulan Desember 2019, ditemukan bahwa formulir rekam medis yang digunakan Puskesmas Kartasura, jika dianalisis dari aspek anatomi belum sesuai dengan ketentuan yang ada yaitu pada bagian heading belum tercantum nomor kode revisi dan nomor halaman. Selain itu, pada formulir rekam medis juga tidak terdapat instruction mengenai jumlah lembar, cara pengisian dan pengiriman. Tidak adanya nomor halaman menyebabkan penyusunan dilakukan secara acak yang penting rapi. Hal ini akan sangat menyulitkan petugas yang akan menggunakan formulir karena harus membolak balik lembar demi lembar formulir yang akan diisi. Sehingga waktu dan tenaga akan terbuang percuma hanya untuk mencari lembar formulir. Padahal setiap harinya, jumlah kunjungan pasien bisa mencapai rata-rata 150 orang per hari.Petugas pada bagian rawat inap banyak menemui kesulitan dan kendala terutama pada saat mencari lembar formulir rekam medis ringkasan masuk dan keluar. Hal tersebut juga dikeluhkan oleh Kepala Puskesmas, karena pelayanan Puskemas menjadi lebih lama, tidak efektif dan efisien serta berdampak pada kualitas mutu pelayanan kesehatan yang diberikan Berdasarkan masalah tersebut, maka penulis tertarik untuk mengambil judul penelitian tentang Analisis Desain Formulir Resume Medis Ditinjau Dari Aspek Fisik Isi Dan Anatomi Di Unit Rawat Inap UPTD Puskesmas Kartasura.

\section{METODE PENELITIAN}

Jenis Penelitian ini menggunakan desain penelitian deskriptif dengan pendekatan studi kasus untuk memberikan hasil analisis desain yang sesuai.

Subjek dan objek dalam penelitian ini, Subjek dalam penelitian ini adalah petugas yang melakukan pengisian form ringkasan masuk dan keluar, diantaranya adalah Dokter (1 orang) perawat (1 orang) dan petugas rekam medis (1 orang).Objek Penelitianyang diambil dalam penelitian ini adalah formulir ringkasan masuk dan keluar di Unit Rawat Inap Puskesmas Kartasura pada tahun 2019.

Uji keabsahan data dalam penelitian kualitatif meliputi uji credibility (validitas internal), transferability (validitas eksternal), dependability (reliabilitas), dan confirmability (objektivitas).

\section{HASIL}

Berdasarkan hasil penelitian yang dilakukan, desain formulir ringkasan masuk dan keluar (resume medis) UPTD Puskesmas Kartasura dapat dilihat dari beberapa aspek, antara lain:

1) Aspek Fisik

Hasil observasi aspek fisik formulir ringkasan masuk dan keluar (resume medis) dari $1 \mathrm{di}$ UPTD 
Puskesmas Kartasura adalah sebagai berikut:

Tabel 1. Desain Formulir dari Aspek Fisik

\begin{tabular}{cll}
\hline No & Jenis & \multicolumn{1}{c}{ Keterangan } \\
\hline 1 & Bahan & Bahan yang digunakan adalah kertas buram 60 gram \\
2 & Bentuk & Bentuk kertas yang digunakan adalah persegi Panjang \\
3 & Ukuran & Ukuran kertas yang digunakan adalah panjang $34 \mathrm{~cm}$ dan lebar $21,5 \mathrm{~cm}$ \\
4 & Warna & Warna dasar kertas yang digunakan adalah abu-abu dengan tulisan tinta \\
& & hitam
\end{tabular}

Sumber: Data Primer, 2020

a. Bahan

Jenis bahan kertas formulir ringkasan masuk dan keluar (resume medis) di UPTD Puskesmas Kartasura menggunakan kertas buram, hal ini menunjukkan bahwa bahan kertas formulir belum sesuai dengan standar yaitu kertas HVS.Sifat kertas buram lebih mudah robek, rentan terhadap minyak dan mudah lusuh (Triyanti, 2018).

b. Bentuk

Formulir ringkasan masuk dan keluar (resume medis) di UPTD Puskesmas Kartasura sudah baik, berbentuk persegi panjang yang sesuai dengan standar dokumen rekam medis.Pada umumnya penggunaan formulir berbentuk standar karena akan mudah untuk diarsipkan atau diperbanyak (Triyanti, 2018).

c. Ukuran

Formulir ringkasan masuk dan keluar (resume medis) di UPTD Puskesmas Kartasura memiliki ukuran panjang $34 \mathrm{~cm}$ dan lebar 21,5 cm sudah sesuai standar formulir yang digunakan pada dokumen rekam medik. Triyanti (2018) menyatakan bahwa formulir rekam medis harus memiliki ukuran kertas yang sama, biasanya kertas ukuran A4.

d. Warna

Formulir ringkasan masuk dan keluar (resume medis) di UPTD Puskesmas Kartasura menggunakan kertas buram yang bewarna abu-abu dengan menggunakan tinta bewarna hitam. Pemilihan warna untuk formulir belum sesuai dengan standar,

Penggunaan kertas berwarna untuk formulir lebih menarik, tetapi kertas bewarna biasanya lebih mahal daripada kertas putih(Triyanti, 2018).Pemilihana kertas pada formulir ringkasan masuk dan keluar (resume medis) di UPTD Puskesmas Kartasura belum sesuai, minimal bewarna putih agar lebih mudah terbaca, sedangkan pemilihan tinta hitam sudah sesuai dengan ketentuan.

\section{2) Aspek Anatomi}

Hasil observasiaspek anatomi formulir ringkasan masuk dan keluar (resume medis) dari $1 \mathrm{di}$ UPTD Puskesmas Kartasura adalah sebagai berikut: 
Tabel 2. Desain Formulir dari Aspek Anatomi

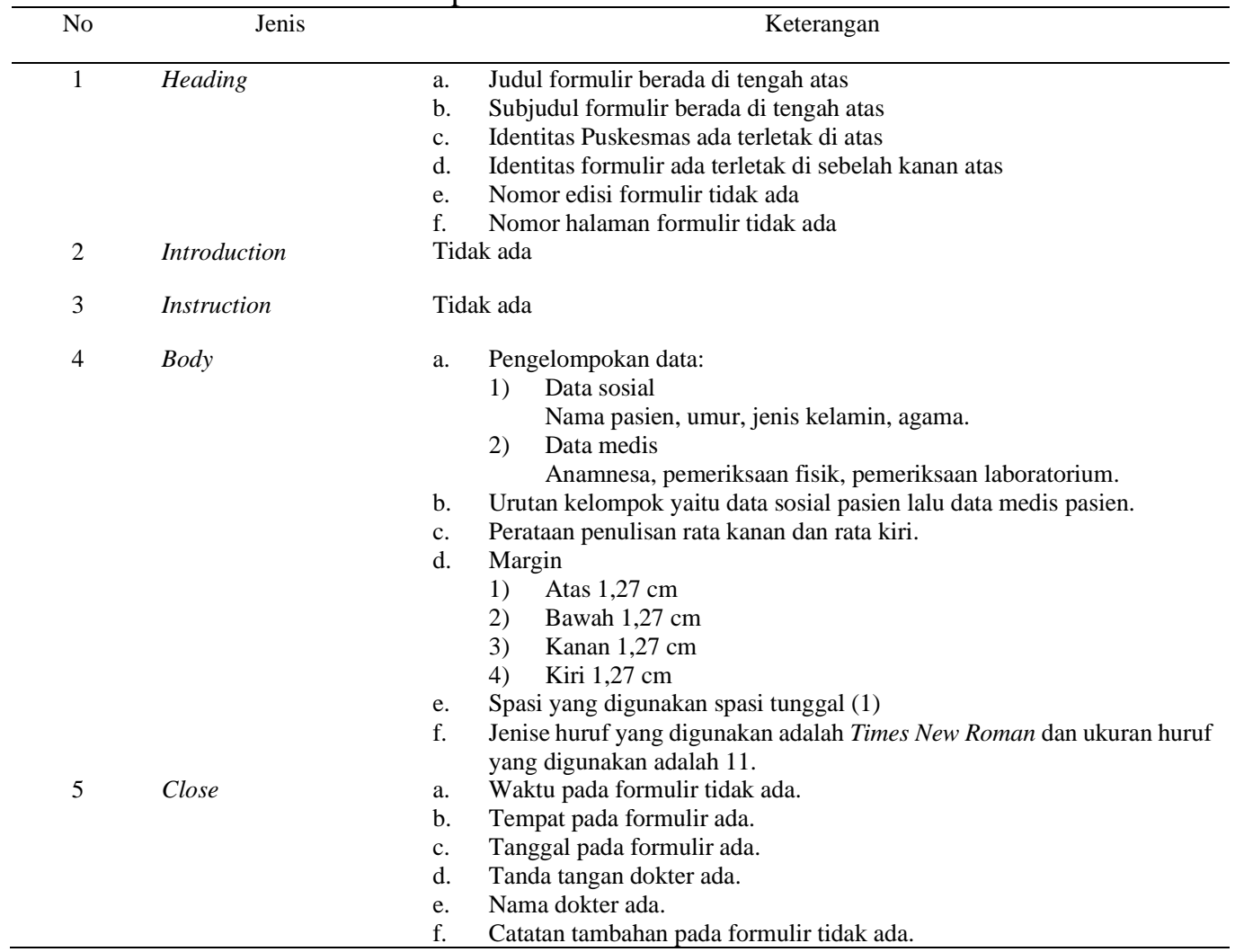

Sumber: Data Primer, 2020

\section{a. Heading}

Heading pada formulir ringkasan masuk dan keluar (resume medis) di UPTD Puskesmas Kartasura sudah baik terdapat nama rumah sakit, alamat, nomor telepon dan alamat email puskesmasyang ditulis di bagian atas tengah. Akan tetapi pada formulir belum ada nomor edisi formulir dan nomor halaman formulir.

Pada file terlihat, judul harus berada di atas sehingga informasi kontrol yang berhubungan bisa terlihat di bagian dasar (Triyanti, 2018).

b. Introduction

Introduction pada formulir ringkasan masuk dan keluar (resume medis) di UPTD Puskesmas Kartasura tidak ada.pernyataan yang jelas bisa dimasukkan di dalam formulir untuk menjelaskan tujuannya (Triyanti, 2018).

\section{c. Instruction}

Instruction pada formulir ringkasan masuk dan keluar (resume medis) di UPTD Puskesmas Kartasura tidak ada.

Instruksi bisa diletakkan pada bagian depan formulir kalau terdapat tempat yang cukup (Triyanti, 2018).

d. Body

1) Pengelompokan dan urutan data

Pengelompokan data pada formulir ringkasan masuk dan keluar (resume medis) di UPTD Puskesmas Kartasura sudah sesuai dengan ketentuan yang ada.

2) Perataan penulisan dan margin Margin yang digunakan belum sesuai dengan standar yang ada karena batas tepi 
kertas lebih kecil dari yang seharusnya.Menurut Triyanti (2018), margin kiri jarak yang layak adalah $2 \mathrm{~cm}$ dengan pertimbangan bagian margin kiriakan dilubangi untuk file (punching hole).

3) Spasi

Spasi yang digunakan adalah 1 spasi serta semua tulisan sudah dapat dibaca dengan jelas. Spasi adalah ukuran area entri data yang dibuat dengan menyesuaikan kebutuhan saat pengisian sehingga tidak akan menemui kesulitan saat pengisian (Triyanti, 2018).

4) Jenis dan ukuran huruf

Jenis huruf yang Times New Romandengan ukuran 11 sudah efektif karena tulisan mudah dibaca. e. Close

Formulir ringkasan masuk dan keluar (resume medis) pada bagian closedi sudah. Pada bagian close formulir belum ada item jam dan catatan tambahan.

Komponen utama terakhir formulir kertas adalah close atau penutup. Ini merupakan ruangan untuk tanda tangan pengontentikasi atau persetujuan (Triyanti, 2018).

\section{3) Aspek Isi}

Hasil observasiaspek isi formulir ringkasan masuk dan keluar (resume medis) dari 1 di UPTD Puskesmas Kartasura adalah sebagai berikut:

Tabel 3. Desain Formulir dari Aspek Isi

\begin{tabular}{|c|c|c|}
\hline No & Jenis & Keterangan \\
\hline 1 & Kelengkapan butir data & $\begin{array}{ll}\text { a. } & \text { Data identitas pasien } \\
\text { 1) Nama pasien ada } \\
\text { 2) Jenis kelamin ada } \\
\text { 3) Umur ada } \\
\text { 4) Nama DPJP ada } \\
\text { 5) Nama PPJP tidak ada } \\
\text { b. Data medis pasien } \\
\text { 1) Nama bangsal ada } \\
\text { 2) Tanggal masuk dan keluar ada } \\
\text { 3) Nama dokter ada } \\
\text { 4) Diagnosa masuk ada } \\
\text { 5) Anamnesa } \\
\text { 6) Pemeriksaan fisik } \\
\text { 7) Pemeriksaan laboratorium } \\
\text { 8) Pemeriksaan radiologi } \\
\text { 9) Pemeriksaan lain-lain } \\
\text { 10) Perkembangan selama dirawat } \\
\text { 11) Diagnosa akhir } \\
\text { 12) Pengobatan/tindakan } \\
\text { 13) Keadaan pasien saat pulang } \\
\text { 14) Anjuran } \\
\text { 15) Sebab kematian }\end{array}$ \\
\hline 2 & Terminologi/istilah & $\begin{array}{l}\text { Istilah pada formulir ada yaitu diagnose, anamnesa, komplikasi, } \\
\text { pemeriksaan radiologi, pemeriksaan laboratorium }\end{array}$ \\
\hline 3 & Singkatan & Singkatan pada formulir ada yaitu th, bln, hr, L/P \\
\hline 4 & Simbol & Tidak ada simbol dalam formulir \\
\hline
\end{tabular}

Sumber: Data Primer, 2020 
a. Kelengkapan butir data

Kelengkapan butir data pada formulir ini sudah sesuai dengan ketentuan yang ada.

b. Terminologi/istilah

Terminologi/istilah pada formulir resume medis mudah dipahami oleh tenga medis dan tidak mengalami kesulitan pada saat pengisian.

c. Singkatan

Singkatan pada formulir resume medis meliputi penanggalan yaitu th, bln, hr dan penggolongan jenis kelamin yaitu $\mathrm{L} / \mathrm{P}$. d. Simbol

Formulir resume medis di UPTD Puskesmas Kartasura tidak mencantumkan simbol.

\section{PEMBAHASAN}

Ketidaklengkapan Formulir Ringkasan Masuk dan Keluar (Resume Medis)

Hasil observasi terhadap ketidaklengkapan formulir resume medis dari 1 di UPTD Puskesmas Kartasura adalah sebagai berikut:

Tabel 4. Persentase Ketidaklengkapan Formulir Resume Medis

\begin{tabular}{|c|c|c|c|}
\hline No & $\begin{array}{ll}\text { Pengisian } \\
\end{array}$ & $\begin{array}{c}\text { Lengkap/ } \\
\text { Baik } \\
(\%)\end{array}$ & $\begin{array}{c}\text { Tidak Lengkap/ Tidak Baik } \\
(\%)\end{array}$ \\
\hline \multirow[t]{3}{*}{1} & Identifikasi & 73,33 & 27,67 \\
\hline & Nama & 100,00 & 0 \\
\hline & Nomor RM & 73,33 & 27,67 \\
\hline \multirow[t]{5}{*}{2} & Pelaporan & 6,67 & 93,33 \\
\hline & Tanggal & 73,33 & 27,67 \\
\hline & Waktu & 13,33 & 86,67 \\
\hline & Diagnosa & 86,67 & 13,33 \\
\hline & Kode & 93,33 & 6,67 \\
\hline \multirow[t]{3}{*}{3} & Autentifikasi & 86,67 & 13,33 \\
\hline & Tanda tangan & 100,00 & 0 \\
\hline & Nama terang & 86,67 & 13,33 \\
\hline \multirow[t]{4}{*}{4} & Pencatatan & 20,00 & 80,00 \\
\hline & Jelas & 60,00 & 40,00 \\
\hline & Coretan & 53,33 & 46,67 \\
\hline & Singkatan & 40,00 & 60,00 \\
\hline \multicolumn{2}{|c|}{$\begin{array}{l}\text { Formulir Ringkasan Masuk Dan Keluar (Resume } \\
\text { Medis) }\end{array}$} & 0 & 100,00 \\
\hline
\end{tabular}


Persentase ketidaklengkapan tertinggi pada pengisian bagian pelaporan $(93,33 \%)$ dan pada pencatatan yang tidak dilakukan dengan baik (80\%). Penulisan yang dilakukan secara lengkap adalah pada bagian penulisan nama pasien dan tanda tangan dokter yaitu $100 \%$. Selain itu, pengisian item diagnosa dan kode memiliki nilai persentase kelengkapan yang tinggi yaitu masing-masing $86,67 \%$ dan $93,33 \%$. Pengisian formulir ringkasan masuk dan keluar (resume medis) di UPTD Puskesmas Kartasura belum sesuai dengan tata cara penyelenggaraan rekam medis. Formulir rekam medis berguna dalam pelayanan berikutnya dengan melihat riwayat pasien sebelumnya oleh karena itu catatan rekam medis haruslah lengkap (Puspitasari, 2017).

\section{KESIMPULAN}

1. Dari aspek fisik tinta yang digunakan berwarna hitam, kertas yang digunakan jenis kertas buram 60 gram berbentuk persegi panjang dengan panjang ukuran $34 \mathrm{~cm}$ x $21,5 \mathrm{~cm}$.

2. Dari aspek anatomi heading ditunjukan formulir yang berisi logo, nama, alamat puskesmas, telepon terletak di tengah atas formulir dan belum ada nomor edisi formulir dan nomor halaman. Introduction daninstruction pada formulir belum ada, body yang terdiri dari margin atas $1,27 \mathrm{~cm}$, margin kanan $1,27 \mathrm{~cm}$, margin kiri 1,27 cm, margin bawah $1,27 \mathrm{~cm}$, spacing menggunakan spasi $1 \mathrm{~cm}$, jenis huruf menggunakan Times New Roman berukuran 11. Close terdiri dari tempat, tanggal, bulan, tahun, nama dan tanda tangan dokter yang merawat tetapi tidak ada waktu pencatatan.

3. Dari aspek isi, kelengkapan butir data terdiri dari data demografi pasien dan data medis pasien, terminologi/istilah medis dan singkatan ada dan mudah untuk dipahami, pada formulir tidak ada simbol.

4. Pengisian formulir ringkasan masuk dan keluar (resume medis) secara keseluruhan belum lengkap karena pada bagian pelaporan terutama item waktu banyak yang terlewati serta pencatatn belum dilakukan secara baik karena banyak penulisan data yang tidak jelas dan banyak singkatan.

\section{UCAPAN TERIMAKASIH}

Selama pelaksanaan penelitian ini, banyak pihak yang telah berjasa dalam memberikan kesempatan, memotivasi, waktu serta pikiran. Ucapan terimakasih penulis sampaikan kepada:

1. Ibu Titik Haryanti, SKM, M.Pd. selaku Dekan Fakultas Kesehatan Masyarakat Universitas Veteran Bangun Nusantara Sukoharjo.

2. Bapak Fahmi Hakam, S.KM., M.P.H selakuKetua Prodi D3 Rekam Medis dan Informasi Kesehatan.

3. Ibu ArifatunNisaa, S.KM., M.P.H. selaku Pembimbing I dalam penyusunan laporan KTI Universitas Veteran Bangun Nusantara Sukoharjo.

4. Ibu Julia Pertiwi, S.KM., M.K.M. selaku Pembimbing II dalam penyusunan laporan KTI Universitas Veteran Bangun Nusantara Sukoharjo.

5. Ibu drg. Endang Astuti selaku Kepala Puskesmas Kartasura

6. Semua pihak yang telah banyak membantu terselesaikannya KTI.

\section{DAFTAR PUSTAKA}

Arianto, N. (2014). Perancangan Uang Formulir Rekam Medis Ringkasan Masuk dan Keluar di Rumah Sakit Umum Mawar Banjarbaru Tahun 2014. STIKES Husada Borneo Banjarbaru.

Indradi, R. (2014). Pengertian Dasar 
Rekam Medis. In Modul Rekam Medis (pp. 19-85). http://repository.ut.ac.id/4092/1/ASI P4315-M1.pdf

Undang - Undang Peraturan Menteri Kesehatan Republik Indonesia Nomor 269, 269 (2008).

Malan, A. (2017). Analisis Kelengkapan Berkas Rekam Medis Rawat Jalan di Puskesmas Gamping I Sleman Yogyakarta.

Mangentang, F. R. (2015). Kelengkapan Resume Medis dan Kesesuaian Penulisan Diagnosis Berdasarkan ICD-10 Sebelum dan Sesudah JKN di RSU Bahteramas. Jurnal ARSI, l(44), 159-168.

Meigian, A. H. (2014). Analisis Kelengkapan Pengisian Resume Medis Pasien Hyperplasia of Prostate pada Dokumen Rekam Medis Rawat Inap di Rumah Sakit Mulia Hati Wonogiri Tahun 2013.

Mulyati, S. (2015). Analisis Desain Formulir Ringkasan Masuk dan Keluar Rawat Inap (RM1) di RSUD Brebes Tahun 2015. Universitas Dian Nuswantoro.

Murni, T., Suhartina, I., \& Dwi, I. (2019). Analisis Kuantitatif Ketidaklengkapan Pengisian Resume Medis Berdasarkan Program Quality Assurance (Suatu Studi di Rumah Sakit Delta Surya Sidoarjo). Jurnal Kesehatan Vokasional, 4(2), 80-89. https://doi.org/10.22146/jkesvo.4394 8

Nurliani, A., \& Imas, M. (2017). Analisis Kuantitatif Kelengkapan Dokumen Rekam Medis Rawat Inap Formulir Ringkasan Masuk Dan Keluar Periode Triwulan IV Tahun 2015.
Jurnal Persada Husada Indonesia, 4(12), 25-46.

Peraturan Menteri Kesehatan Republik Indonesia Nomor 75, Pub. L. No. 75, Pusat Kesehatan Masyarakat 132 (2014).

Purwaningsih, D. (2017). Analisis Desain Formulir Rekam Medis di RS PKU Muhammadiyah Wonosari Tahun 2017 [STIKES Jenderal Achmad Yani Yogyakarta]. https://doi.org/10.1002/ejsp.2570

Puspitasari, E. (2017). Desain Formulir Rekam Medis Pasien Rawat Jalan di Puskesmas Kauman Kabupaten Ponorogo. Global Health Science, 2(2), 155-164.

Saputra, Y. R., \& Setijaningsih, R. A. (2013). Analisis Desain Formulir Lembar Masuk dan Keluar RSIA Gunung Sawo Semarang Tahun 2013.

Sugiyono. 2005. Memahami Penelitian Kualitatif. Bandung: CV. Alfabeta

Susanto, E., Styowati, L. U., Kasimin, \& Ningrum, K. P. A. (2016). Studi Deskriptif Kelengkapan Pengisian Resume Medis Rawat Inap. Seminar Nasional Rekam Medis Dan Informasi Kesehatan "Peningkatan Mutu Perekam Medis Dan Informasi Kesehatan," 71-77.

Susantyo, A. 2018. Buku Ajar MIK III. Sekolah Tinggi Ilmu Kesehatan Widya Cipta Husada.

Triyanti, E., \& Weningsih, I. R. (2018). Bahan Ajar Rekam Medis dan Informasi Kesehatan (RMIK). In Pusat Pendidikan Sumber Daya Manusia kesehatan Badan Pengembangan dan Pemberdayaan 
Sumber Daya Manusia Kesehatan (1st ed.). Kementerian Kesehatan Republik Indonesia.

Wariyanti, A. S., Harjanti, H., \& Sugiarsi, S. (2019). Potret Kelengkapan Rekam Medis Puskesmas Sebelum dan Setelah Akreditasi. Jurnal Manajemen Informasi Kesehatan Indonesia, 7(2), 152-157.

Widjaya, L. (2018). Bahan Ajar Rekam Medis dan Informasi Kesehatan (RMIK) - Manajemen Mutu Informasi Kesehatan III "Pendokumentasian
Rekam Medis" (I). Pusat Pendidikan Sumber Daya Manusia Kesehatan Badan Pengembangan dan Pemberdayaan Sumber Daya Manusia Kesehatan Kementerian Kesehatan Republik Indonesia.

Zahra, N. A. (2016). Analisis Kelengkapan Pengisian Identitas Pasien Pada Formulir Lembar Masuk Dan Keluar Pasien Rawat Inap Ruang E2 Guna Menunjang Mutu Rekam Medis Di RSUD Cibabat Cimahi. Politeknik TEDC Bandung. 